\section{Compreendendo a Educação Popular em Saúde: um estudo na literatura brasileira}

\author{
Understanding Popular Health Education: \\ a review of the Brazilian literature
}

\author{
1 Centro de Ciências Médicas, \\ Universidade Federal da \\ Paraíba, João Pessoa, Brasil. \\ 2 Faculdade de Ciências \\ Médicas da Paraíba, João \\ Pessoa, Brasil. \\ 3 Faculdade de Medicina \\ Universidade Federal do Rio \\ de Janeiro, Rio de Janeiro, \\ Brasil. \\ Correspondência \\ L. B. Gomes \\ Departamento de Promoção \\ da Saúde, Centro de Ciências \\ Médicas, Universidade Federal \\ da Paraíba. \\ Cidade Universitária, João \\ Pessoa, PB 58051-900, Brasil. \\ lucianobgomes@gmail.com
}

\begin{abstract}
This article reviews the Brazilian literature on popular health education, a theoretical area that includes a relevant group of the country's public health researchers and political activists. This was a qualitative, exploratory, analytical study. Based on a search in the SciELO database and books and book chapters, we systematized the academic output on popular health education in Brazil. The article discusses the historical process in which popular health education was constructed by various social movements. We further analyze the general characteristics of popular health education and its main agendas, the ways by which authors with this perspective view the educational work of health services for the population, and their critiques and disputes with the hegemonic approach to the organization of education and health care. Finally, we identify several additional contributions to popular health education's foundations and principles.
\end{abstract}

Health Education; Consumer Participation; Qualitative Research
Luciano Bezerra Gomes 1,2 Emerson Elias Merhy 3

O campo da saúde no Brasil constituiu-se como um terreno de intensos debates quando toma por foco a organização das políticas públicas para esta área. São muitos os sujeitos políticos que, com distintas inserções institucionais, constroem formulações no intuito de disputar nessa arena. Entretanto, em relação à maneira como se posicionam e no modo como são construídas as formulações, muitas vezes essas disputas ficam relativamente veladas. Por um lado, o fato de a saúde coletiva brasileira ter se fortalecido como área de produção acadêmica, com diversos grupos de pesquisa vinculados a conceituadas instituições formadoras, leva a que os debates tomem um caráter mais "científico". Nesse sentido, a dimensão política inerente às proposições que são realizadas se limita a uma "honestidade" teórica em que se reconhece a "parcialidade" do conhecimento produzido. De certo modo, assumidas como perspectivas teóricas, as distintas formulações políticas se isolam entre as escolas, fomentando discussões que ficam no campo epistêmico em torno de aspectos metodológicos.

Na produção científica em geral, mas no campo da saúde em especial, as produções acadêmicas não apenas estão se assentando em métodos que têm relação com a concepção de mundo dos seus pesquisadores; as escolhas dos autores, de certa forma, delimitam o campo político no qual eles pretendem debater. Não há delimitação de objeto de pesquisa, há sempre definição política em torno de saber em que disputas estamos 
entrando e com quem as estamos travando. Dessa forma, acreditamos que não debatemos apenas teorias, de fato, estamos sempre disputando a construção dos sujeitos, a produção da subjetividade dos atores presentes nas arenas. A formulação acadêmica é, intensamente, produção de disputas 1,2 .

É dentro dessas perspectivas que desenvolvemos uma pesquisa, como parte do mestrado de um de seus autores junto ao Programa de Pósgraduação em Clínica Médica da Faculdade de Medicina da Universidade Federal do Rio de Janeiro. O presente artigo é parte dessa pesquisa, e teve o papel, nela, de delimitar melhor o campo de produção da matriz teórica da educação popular em saúde, vista como fruto de refinamento de formulações teóricas da educação aplicadas à saúde e, principalmente, como ferramenta para a luta social de diversos sujeitos articulados em vários movimentos sociais, disputando os rumos das políticas sociais no Brasil e na América Latina.

A intenção de pesquisar entre autores da educação popular em saúde se dá em virtude do reconhecimento da força que tem esta matriz teórica no campo da saúde. Um indicador disso poderia ser a reconhecida influência de suas formulações entre pesquisadores da saúde presentes na academia brasileira. Suas construções teóricas têm apresentado a capacidade de produzir significado e constituir novos sujeitos nesse campo. Um segundo aspecto que nos leva a estudar essa corrente de pensamento se dá pelo fato de que muitas das formulações desenvolvidas nesse campo de produção têm sido agregadas em diversas experiências onde se tenta implementar o SUS. Outro motivo é que, em parte das experiências de implementação do SUS que se basearam em suas formulações, diversos autores dessa matriz teórica se envolveram diretamente. Certamente, isso tendo refletido, em termos práxicos, em seus movimentos de (re)formulações teóricas. Por fim, concordando com Gilles Deleuze ${ }^{3}$, para quem só escrevemos algo porque nos é necessário, de certa forma, com este estudo, dialogamos com algumas das vivências em que participamos. Nas várias inserções como profissionais e militantes da saúde, a educação popular em saúde sempre tem se apresentado como uma das frentes que mais tem agregado novos sujeitos políticos na saúde; as obras de seus autores são intensamente acessadas por muitos companheiros e eles sempre se colocaram, direta ou indiretamente, como interlocutores necessários e privilegiados.

\section{Algumas opções metodológicas}

Este estudo pode ser caracterizado como uma pesquisa de natureza qualitativa, de nível exploratório e de caráter analítico. Segundo Gil 4 (p. 43), a pesquisa exploratória tem "como principal finalidade desenvolver, esclarecer e modificar conceitos e idéias, tendo em vista a formulação de problemas mais precisos ou hipóteses pesquisáveis para estudos posteriores". Entre as diversas técnicas de pesquisa qualitativa possíveis para obtenção dos dados, foram utilizados métodos de pesquisa bibliográfica. A pesquisa bibliográfica é "um apanhado geral sobre os principais trabalhos já realizados, revestidos de importância por serem capazes de fornecer dados atuais e relevantes relacionados com o tema" 5 (p. 12).

Para a realização desta pesquisa, inicialmente fizemos um levantamento bibliográfico preliminar, no qual tentamos identificar as características gerais da educação popular em saúde. Para tanto, realizamos uma revisão de artigos publicados até o mês de junho de 2009 em revistas indexadas e disponíveis na página virtual da base de dados da Scientific Electronic Library Online (SciELO). Para a identificação do material, foram feitas buscas com a utilização das seguintes palavras-chave: educação popular em saúde; educação popular e saúde; educação em saúde; educação em saúde bucal; educação em saúde na escola; educação em saúde publica; educação em serviços de saúde; educação para saúde; educação sanitária; educação sanitária odontológica.

Foram identificados, inicialmente, 375 artigos, os quais tiveram seus títulos, autores e resumos lidos, resultando em uma segunda seleção de 90 artigos que poderiam apresentar relação com o objetivo deste levantamento bibliográfico preliminar e que foram selecionados para leitura exploratória, na tentativa de identificar os que tinham provável capacidade de contribuir com a caracterização da matriz teórica da educação popular em saúde. Com base nisso, realizamos uma leitura seletiva e posterior leitura analítica dos 27 artigos mais relevantes para os objetivos deste estudo. Por meio desses artigos foram identificados livros e capítulos de livros, além de mais 10 artigos que não constavam na SciELO, que eram citados com mais relevância, e que levaram a uma segunda seleção de materiais que totalizaram 37 artigos, 15 livros e 25 capítulos de livros. Todo esse material passou por etapas semelhantes de leituras exploratória, seletiva e analítica. As primeiras leituras foram necessárias para selecionar, entre toda a produção, os materiais que teriam potencial de contribuir com a caracterização das questões centrais para essa corrente de 
pensamento. As leituras mais profundas foram realizadas já com a intenção de analisar e interpretar o material selecionado, com a finalidade de construir sínteses capazes de expor a construção teórica presente na educação popular em saúde. À medida que as leituras foram se sucedendo, realizamos apontamentos e fichamentos, os quais foram armazenados digitalmente, sendo posteriormente organizados logicamente a fim de permitir a redação do artigo 6 .

Para realização da leitura analítica e interpretativa utilizamos como referência alguns aspectos teóricos da hermenêutica filosófica. Para essa perspectiva, a compreensão de algo é a própria interpretação, vista como uma condição do ser humano e não como resultado da aplicação criteriosa e padronizada de determinado método $a$ priori. Para tanto, essa corrente de pensamento admite que, para se produzir uma compreensão, é necessário reconhecer o engajamento dos sujeitos, pois é a partir do diálogo de suas concepções com aquilo que tenta entender que a compreensão é negociada, testando-se aí inclusive nossas idéias e preconcepções. Não existe um significado objetivo, o qual tentamos alcançar nos distanciando do que somos para assimilálo imparcialmente. Sendo assim, não há uma interpretação correta das ações humanas e dos textos; não se desvenda algo; não se reproduz algo pela interpretação; sempre se constrói uma compreensão no diálogo com o que já se traz. Nesse sentido, a compreensão torna-se, em si, uma experiência prática, humana, deixando de ser um movimento em etapas de algo que é assimilado para depois ser aplicado 7 .

Em um texto em que analisa o debate que se trava entre Habermas e Gadamer, Minayo 8 (p. 221-2, grifos da autora) retoma os pressupostos metodológicos da hermenêutica para as ciências sociais, quais seriam: “a) o pesquisador tem que aclarar para si mesmo o contexto de seus entrevistados ou dos documentos a serem analisados. Isso é importante porque o discurso expressa um saber compartilhado com outros, do ponto de vista moral, cultural e cognitivo. b) O estudioso do texto (o termo texto aqui é considerado no sentido amplo: relato, entrevista, história de vida, biografia etc.) deve supor a respeito de todos os documentos, por mais obscuros que possam parecer à primeira vista, um teor de racionalidade e de responsabilidade que não lhe permite duvidar. O intérprete toma a sério, como sujeito responsável o ator social que está diante dele. c) O pesquisador só pode compreender o conteúdo significativo de um texto quando está em condições de tornar presentes as razões que o autor teria para elaborá-lo. d) Por outro lado, ao mesmo tempo em que o analista busca entender o texto, tem que julgá-lo e tomar posição em relação a ele. Isto é, qualquer intérprete deve assumir determinadas questões que o texto lhe apresenta como problemas não resolvidos. E compenetrar-se do fato de que no labor da interpretação não existe última palavra. e) Toda interpretação bem sucedida é acompanhada pela expectativa de que o autor poderia compartilhar da explicação elaborada se pudesse penetrar também no mundo do pesquisador. Tanto o sujeito que comunica como aquele que o interpreta são marcados pela história, pelo seu tempo, pelo seu grupo. Portanto, o texto reflete esta relação de forma original".

Tentamos tomar esses passos como referência no trabalho com o material bibliográfico neste estudo. Também, consideramos algumas sugestões metodológicas propostas por Umberto Eco ${ }^{9}$, em especial em relação à maneira de organizar a leitura de material bibliográfico e de como organizar os fichamentos, otimizando a etapa de redação da versão final do texto.

Com base nessa pesquisa bibliográfica, elaboramos uma sistematização da produção da educação popular em saúde, apresentando um resgate do processo histórico de constituição da educação popular em saúde como fruto da atuação de diversos movimentos sociais, uma descrição das características gerais da educação popular em saúde, suas grandes pautas, a maneira como os autores desta perspectiva compreendem a atuação educativa dos serviços de saúde junto à população, suas críticas e disputas com o modo hegemônico de se organizar a educação e a atenção à saúde, bem como algumas contribuições que agregam aos que se propõem a seguir suas bases e preceitos.

\section{Compreendendo a Educação Popular em Saúde}

O percurso das ações de educação em saúde no Brasil tem suas raízes nas primeiras décadas do século XX. As campanhas sanitárias da Primeira República e a expansão da medicina preventiva para algumas regiões do país, a partir da década de 1940, no Serviço Especial de Saúde Pública apresentavam estratégias de educação em saúde autoritárias, tecnicistas e biologicistas, em que as classes populares eram vistas e tratadas como passivas e incapazes de iniciativas próprias 10 .

Até a primeira metade da década de 1970, a prática de atenção à saúde se resumia quase que exclusivamente à medicina privada, para os que podiam pagar; e nos hospitais da previdência social, para os trabalhadores que tinham carteira assinada, em ambas as situações desenvolvendo práticas de caráter basicamente curativas. As 
práticas preventivas e educativas em saúde se davam de forma isolada. As condições de saúde das classes pobres eram péssimas e não refletiam o crescimento econômico que o país apresentara nos últimos anos. A crescente insatisfação política desencadeou um processo de instabilidade social que obrigou o Estado a voltar um pouco sua atenção aos problemas mais básicos da população. É a partir daí que, na tentativa de oferecer uma medicina curativa para os mais carentes, começa a ser implementada no Brasil uma proposta de medicina comunitária que empregava técnicas simplificadas, de baixo custo, e valorizava os aspectos preventivos da saúde. Nessa política de saúde, são criados vários postos e centros de saúde em muitas regiões e cidades periféricas dos grandes e médios centros de desenvolvimento. Nesses espaços os profissionais de saúde se viram diante da necessidade de atuar próximos da realidade das pessoas que eles atendiam, e passaram a se integrar na dinâmica da vida das classes populares 11 .

O lento processo de abertura política do país se deu a partir da segunda metade da década de 1970. Sem partidos e sindicatos onde se aglutinar para resistir e construir um novo modelo para a sociedade, a população busca novas formas de se organizar. A Igreja Católica, em virtude das formulações dos teóricos da teologia da libertação e por escapar em alguns aspectos da rede direta de repressão mobilizada pelo Estado, foi uma das instituições que permitiu a reunião de pessoas com objetivos transformadores e possibilitou trocas de experiências entre diversas áreas do conhecimento e segmentos da sociedade. Nesse período, foram muitos os movimentos nos quais os profissionais de saúde se engajaram, vários deles baseados em uma relação menos vertical entre os profissionais e a sociedade, inspirados nos conceitos da educação popular, sistematizados inicialmente por Paulo Freire e depois se abrindo toda uma área de produção de conhecimentos vinculados às suas práticas, denominada educação popular em saúde 12 .

O processo de reforma sanitária se dá por meio de várias lutas políticas e institucionais que se intensificaram durante toda a década de 1980, contando com a participação de vários profissionais que haviam desenvolvido experiências inovadoras na organização da atenção à saúde, muitos dos quais passaram a ocupar posições de gestão em algumas administrações públicas mais progressistas. Esse movimento também contou com a colaboração de algumas lideranças políticas e de organizações da sociedade civil.

No ano de 1986, realizou-se a VIII Conferência Nacional de Saúde, grande marco político e teórico do processo de reestruturação da saúde pública da década de 1980. Com base nas propostas surgidas lá, criou-se, em 1987, o Sistema Unificado e Descentralizado de Saúde (SUDS), que garantiu o atendimento universal nos serviços de atenção básica e rede de hospitais públicos e conveniados, iniciando um processo de descentralização de poder e desconcentração de recursos ao fortalecer as gestões estaduais 13,14.

A Constituição Federal de 1988 afirma, no seu art. 196 15, que a saúde é um direito universal e responsabiliza o Estado pela realização de políticas públicas intersetoriais que a garantam. Com ela, foi criado o Sistema Único de Saúde, que foi regulamentado com a Lei $n^{o} .8 .080$ 16, de 19 de setembro de 1990, conhecida como Lei Orgânica da Saúde, que definia como alguns dos princípios e diretrizes do SUS: universalidade; integralidade; eqüidade; participação da comunidade; descentralização político-administrativa; regionalização e hierarquização da rede de serviços de saúde. Alguns aspectos de sua regulamentação passaram por vetos presidenciais, e foram revistos a partir da Lei $n^{o} .8 .142$ 17, ainda em 1990, em especial os que tratam da participação popular na gestão e controle do sistema.

A década de 1990 foi de lutas pela efetiva implementação e expansão do SUS e foi marcada por várias conferências de saúde municipais, estaduais e nacionais, além da regulamentação mais detalhada da estrutura e funcionamento do SUS por meio de inúmeras portarias e leis, das normas operacionais básicas e de assistência à saúde 14.

Em 1991, profissionais de saúde, lideranças de movimentos sociais e pesquisadores envolvidos em diversas experiências que se baseavam nos princípios da educação popular se organizaram em torno da Articulação Nacional de Educação Popular em Saúde, que foi constituída no I Encontro Nacional de Educação Popular em Saúde, ocorrido em São Paulo. Em 1998, a Articulação muda de nome para Rede de Educação Popular e Saúde, a qual passa a representar um espaço importante de articulação política, de troca de experiências e de formulação de teorias e de propostas alternativas para o funcionamento dos serviços de saúde. Segundo Stotz et al. 18 (p. 53): “a unidade de propósitos dos participantes do movimento consiste em trazer, para o campo da saúde, a contribuição do pensamento freiriano, expressa numa pedagogia e concepção de mundo centrada no diálogo, na problematização e na ação comum entre profissionais $e$ população. É importante ressaltar, na identidade do pensamento de Paulo Freire e a dos participantes do movimento de educação popular e saúde, a convergência de ideologias aparentemente 
díspares, quais sejam, o cristianismo, o humanismo e socialismo".

No ano de 2003, com o auxílio do Ministério da Saúde no primeiro ano do governo Lula, realizou-se uma nova configuração entre os movimentos sociais que se articulavam em torno da luta pela saúde. Em uma parceria com a Rede de Educação Popular e Saúde, realizaram-se encontros estaduais que culminaram em um encontro nacional no qual se constituiu a Articulação Nacional de Movimentos e Práticas de Educação Popular e Saúde, que ficou conhecida por ANEPS 19.

A Rede de Educação Popular e Saúde continuou a existir de forma autônoma e, a partir de articulações provenientes de seus membros, também constitui-se a Rede de Estudos sobre Espiritualidade no Trabalho em Saúde e na Educação Popular. Essa rede agrega sujeitos que, participando ou não das outras articulações, se interessam em aprofundar-se na temática da espiritualidade em saúde.

Nos últimos anos, o Ministério da Saúde tem apresentado setores específicos para construção de políticas e incentivo a atividades no campo da educação popular em saúde, e também foi criado um grupo de trabalho específico junto à Associação Brasileira de Pós-graduação em Saúde Coletiva (ABRASCO), órgão que congrega as entidades acadêmicas brasileiras que produzem no campo da saúde coletiva 20,21 .

Esse sucinto resgate histórico se fez no intuito de demonstrar que, mais do que sujeitos que produzem uma reflexão acadêmica, no campo da educação popular em saúde, nos deparamos com coletivos que vêm desenvolvendo intensa militância política e social. Para muito além disso, são coletivos que apresentam grande dinamicidade e que têm a capacidade de constituir redes de articulação poderosas em suas capilaridades. Nesses movimentos foram sendo formuladas novas maneiras de se compreender e de realizar processos educativos no setor saúde.

A educação em saúde é, muitas vezes, entendida como um modo de fazer as pessoas do povo mudarem seus hábitos para assimilarem práticas higiênicas e recomendações médicas que evitariam o desenvolvimento de um conjunto de doenças. Entretanto, para os autores que se baseiam na educação popular, educar para a saúde é justamente ajudar a população a compreender as causas dessas doenças e a se organizar para superá-las 11.

A educação popular toma como ponto de partida os saberes prévios dos educandos. Esses saberes vão sendo construídos pelas pessoas à medida que elas vão seguindo seus caminhos de vida e são fundamentais para que consigam superar, em diversas ocasiões, situações de muita adversidade. A educação popular faz uma aposta pedagógica na ampliação progressiva da análise crítica da realidade por parte dos coletivos à proporção que eles sejam, por meio do exercício da participação popular, produtores de sua própria história 21,22.

A educação popular, além de permitir a inclusão de novos atores no campo da saúde, fortalecendo a organização popular, permite também que as equipes de saúde ampliem suas práticas, dialogando com o saber popular ${ }^{20}$. A educação popular em saúde, assim, busca empreender uma relação de troca de saberes entre o saber popular e o científico, em que ambos têm a enriquecer reciprocamente 11 . Segundo diversos autores, essa proposta torna-se cada vez mais necessária, à medida que foi sendo produzido um distanciamento cultural entre as instituições de saúde e a população, fazendo com que uns não compreendam o modo como os outros operam. A educação popular em saúde tem como balizador ético-político os interesses das classes populares, cada vez mais heterogêneas, considerando os movimentos sociais locais como seus interlocutores preferenciais 23 .

A educação popular em saúde busca não apenas a construção de uma consciência sanitária capaz de reverter o quadro de saúde da população, mas a intensificação da participação popular radicalizando a perspectiva democratizante das políticas públicas. Para alguns autores, ela representa um modo brasileiro de se fazer promoção da saúde 21 .

Atualmente, a convivência nos serviços de saúde e os meios de comunicação de larga escala têm representado as grandes conexões que permitem o desenvolvimento de relações educativas entre os trabalhadores de saúde e a população 12 .

\section{Contribuições da educação popular para a educação em saúde}

As análises realizadas com base na educação popular apontam para a leitura de que a medicina não tem se dedicado a compreender os saberes, estratégias e significados que as classes populares desenvolvem diante dos processos de adoecimento para, a partir daí, estruturar modos de agir que integrem o saber popular e os conhecimentos técnico-científicos. Via de regra, ou se confia no bom senso do profissional de saúde ou se produzem trabalhadores específicos para desenvolver medidas sanitárias desarticuladas dos atendimentos individuais, gerando pouco impacto na situação de saúde dos coletivos. Contrapondo-se a isso, a educação em saúde tem 
sido o setor que tem feito buscas no sentido de superar tais práticas, desenvolvendo diversas estratégias de diálogo entre os pensares e fazeres da população e dos profissionais de saúde 12 .

Entretanto, hegemonicamente, as ações de educação em saúde têm se apresentado como importantes instrumentos de dominação e de responsabilização dos indivíduos pelas suas condições de vida 20. Para superar tal situação, propõe-se reorientar as práticas de saúde, de modo que a educação em saúde deixe de ser apenas mais uma oferta pontual dos serviços para ser algo inerente às suas práticas, construindo assim a participação popular no seu cotidiano 12,21.

Para Valla et al. 24 , a rede pública de serviços de saúde existente é muito importante para a manutenção da saúde das classes populares, e isto é reconhecido por elas; entretanto, segundo estes autores, há também a concepção de que muitas questões essenciais à sua saúde não podem ser solucionadas nestes serviços quando funcionam do modo como tradicionalmente eles têm se estruturado.

Nesse contexto, afirmam que a população vem apontando outras formas de se organizar para solucionar seus problemas de saúde, aliviar o sofrimento e construir formas terapêuticas de cuidado integrais. Os usuários têm, cada vez mais, buscado práticas tidas como "alternativas" que permitam compreendê-los e impactar em melhorias de saúde de forma integral. E embora existam diversas práticas que se colocam com tal perspectiva, muitas delas não estão disponíveis nos serviços de saúde ou estão apenas à disposição de parcelas mais abastadas da população. Por isso, torna-se importante compreender e valorizar o modo como essas classes vêm construindo suas alternativas de enfrentamento dos problemas de saúde por meio de diversas estratégias 24,25 .

Nessa perspectiva, a postura do profissional de saúde para com a medicina popular deveria ser de respeito e diálogo, identificando e apontando situações de que se tem conhecimento de malefícios causados à população por algumas técnicas e medicamentos populares, mas valorizando as práticas que representam uma sistematização de conhecimentos que vão se acumulando ao longo de várias gerações. Seria relevante salientar o papel de diversos agentes informais de saúde, os quais apresentam grande respaldo popular e que portam saberes baseados em uma forte cultura, a qual se aprende na dinâmica social. Esses atores podem apresentar alto poder educativo, como os erveiros, as parteiras e as rezadeiras; entretanto, há pessoas que buscam ganhos financeiros, como renomados balconistas de farmácias e práticos odontológicos, que podem ser orientados para evitar danos à população corrigindo eventual má técnica 11.

Práticas como o uso de chás têm sido bastante comuns em áreas de serviços de atenção básica, sendo compreendidas como medidas de autocuidado, com grande autonomia da população para isto 26 . Além de seu caráter terapêutico, segundo Celerino Carriconde 27, o uso de plantas medicinais apresenta relevância: (a) antropológica, por resgatar os saberes populares e, assim, elevar a auto-estima de populações, muitas vezes marginalizadas; (b) pedagógica, por permitir a instituição de uma relação dialógica entre trabalhadores de saúde e usuários que dominam os usos destas plantas medicinais; (c) econômica, permitindo o acesso ao medicamento fitoterápico; (d) ecológica, garantindo a manutenção de plantas que em muitas situações vêm sendo eliminadas pelas plantações com interesse meramente lucrativo. A esse conjunto de valores, acrescentamos aqui a sua relevância social e política, pois, para conseguir as plantas, geralmente as pessoas as procuram junto aos seus vizinhos, fortalecendo a rede de apoio social e permitindo a discussão sobre o adoecimento e estratégias de sua superação na e pela comunidade.

A relação de diálogo diante de práticas como a fitoterapia é relevante, pois identificando os usos das plantas por parte da população, os profissionais podem enriquecer seus arsenais terapêuticos; ao mesmo tempo, podem orientar algumas incorreções no manejo de plantas medicinais que já foram cientificamente comprovadas, como efeitos adversos e contra-indicações de determinadas substâncias. Essa relação permitiria o surgimento de um terceiro saber, fruto da interação entre os conhecimentos dos profissionais de saúde e da população 28 .

Outra ação educativa muito comum são as palestras, modo mais freqüente de realização de práticas coletivas em serviços de saúde. Elas precisariam ser reorientadas para que, ao invés do repasse de normas e orientações de higiene $\mathrm{e}$ boas condutas, tais iniciativas se apresentassem como oportunidades de diálogo entre trabalhadores e usuários, em que os aspectos coletivos da dinâmica comunitária pudessem ser enfatizados 11 .

A formação de grupos de pessoas com determinadas características que as aproximam, seja uma condição de vida, como pertencer a certa faixa etária, ou ser portador de determinada doença, é estratégia também comumente utilizada para desenvolver processos de educação nas unidades de saúde. Um exemplo é a realização de cursos de gestantes que terão seus primeiros filhos, para trocar informações com mulheres experientes e, a partir daí, desenvolver um processo 
de discussão das condições comuns entre estas mulheres. Nem todos os grupos, entretanto, encerrariam a mesma capacidade educativa. Seria preciso, para criar um grupo, primeiro identificar os interesses que mobilizam e os problemas mais relevantes de uma população. Em algumas situações, seria interessante, por exemplo, estruturar um curso sobre determinada temática como mote para se iniciar um grupo com as pessoas envolvidas nestas atividades 11 . Nos grupos organizados a partir de patologias específicas, sua força estaria não no foco na doença, e sim na circulação de emoções, nas trocas que se efetuam no compartilhamento de medos, tristezas, dores e afetações de diferentes modos que se desenvolvem no processo de adoecimento e cura. A circulação desses afetos favoreceria o fortalecimento dos laços e vínculos sociais 25 .

Uma estratégia muitas vezes vista como interessante é a exposição na unidade de saúde de fotos em que se identificam problemas ou onde se registram atuações coletivas da população para resolver determinadas questões, como um mutirão. Em outros casos, expor frases de pessoas da comunidade que tenham a ver com alguma característica da dinâmica social local. Tais medidas visam a estimular as pessoas a pensarem e dialogarem quando vêm à unidade de saúde, quaisquer que tenham sido os motivos que as trouxeram ${ }^{11}$.

Estratégias de realização de diagnóstico e planejamento participativos das ações de saúde podem ser vistas como relevantes para mobilização e conscientização da população, mas também como necessários para que a perspectiva dos moradores possa corrigir distorções criadas pela perspectiva tecnicista, que muitas vezes leva a equívocos relevantes por parte dos profissionais de saúde. Nesse sentido, o diagnóstico e planejamento participativos representariam uma possibilidade de ampliação do diálogo entre o saber popular e o saber técnico-científico 20 .

Em relação às ações coletivas realizadas fora do serviço de saúde, afirma-se que elas variam desde as mais "técnicas" até as mais "políticas". Nelas, as equipes de saúde podem ter caráter mais diretivo ou serem praticamente convocadas pela população para participar. Quanto mais autônomas e mais voltadas para processos coletivos da dinâmica de vida, geralmente mais politizada estaria a população. Entretanto, como as ações coletivas, independentemente de quem as coordena ou do que as motiva, podem tanto promover desenvolvimento social como dificultá-lo, seria importante que fossem bem preparadas e que se tomassem os encaminhamentos adequados para que se desenvolva seu potencial educativo. Geralmente, os grupos que são formados pela população se apresenta com características de prestadores de serviços, de ações reivindicatórias ou de realização de mutirões 11. Uma possibilidade desafiadora seria atuar na perspectiva do duplo caminho onde, ao mesmo tempo em que se reivindica e se responsabiliza os governantes, tenta-se solucionar os problemas com os recursos que consegue mobilizar autonomamente 29.

Progressivamente, entretanto, a criação de grupos e movimentos específicos de saúde foi deixando de ser a estratégia prioritária desenvolvida pelas classes populares, passando a ser mais comum a estruturação de grupos que discutem o tema da saúde diversificando a atuação dentro de organizações mais amplas das classes trabalhadoras 11 .

Um desafio que se reconhece é que, além da atuação junto aos grupos da população, muitas vezes se faz necessário que as equipes de saúde desenvolvam ações políticas junto a instituições locais e lideranças políticas; sejam as que podem estar relacionadas com o desenvolvimento da comunidade, ou então as que têm o papel de manter o serviço para o seu adequado funcionamento. A relação com essas lideranças deveria ser respeitosa, ao mesmo tempo em que se deveria ter clareza dos processos em negociação, a fim de evitar a manipulação das atividades dos serviços públicos de saúde por parte de grupos políticos com interesses privatistas 11 .

Um importante meio de comunicação que é proposto para ampliar a interlocução com a população é o rádio. Além de apresentar elevado alcance, permitindo atingir um grande público de uma só vez, principalmente nas populações mais pobres, geralmente as emissoras de rádio estão acessíveis aos profissionais de saúde e permitem o diálogo com o ouvinte, dinamizando, articulando e aproximando o processo educativo da realidade das populações 11 . Essa estratégia tende a se tornar mais potente em virtude da grande expansão das rádios comunitárias ocorrida nos últimos anos em todo o país.

Uma das ações vistas como relevante para permitir o diálogo e troca de saberes é a realização ou participação em mobilizações que estão ligadas diretamente ao lazer e à interação social, como a organização de festas e eventos comemorativos, bingos etc. Tais ações fortaleceriam a felicidade como projeto de vida para populações que, geralmente, têm muito pouca oferta deste tipo nas áreas onde moram, e demonstrariam uma abertura da equipe para ampliar a concepção de saúde com que atua 26. Brinquedotecas, clubes da terceira idade, rádios comunitárias, oficinas de arte, música e dança, exibição de vídeos, teatros de mamulengo e de rua são algumas das 
ações no setor da cultura popular vistas como iniciativas que poderiam potencializar atividades na perspectiva da educação popular em saúde, e que vão para muito além dos muros dos serviços de saúde 20 .

A educação popular em saúde ajudando a compreender e lidar com as iniciativas autônomas da população: as redes de apoio social no território

Para diversos autores, problemas como o desemprego, a precarização das relações de trabalho, a iniqüidade na distribuição de renda, a violência e a retração de redes sociais contribuem para a intensificação de um ciclo que gira em torno da pobreza, isolamento e adoecimento, e têm levado ao desenvolvimento de um certo sofrimento difuso na população. Esse sofrimento difuso pode elevar a demanda de atenção à saúde e demonstrar os limites do atual modo de se estruturar a atenção à saúde no Brasil 24,30. A atuação dos profissionais de saúde que se baseia na realização de procedimentos vem produzindo uma limitada oferta de ações para lidar com os problemas complexos que se apresentam 25.

O sofrimento difuso se caracterizaria por "uma sensação de mal-estar generalizado com uma diversidade de sintomas, tais como irritabilidade, insônia, nervosismo, ansiedade, angústia, dores no corpo, acrescido da falta de perspectiva de vida" 31 (p. 250). Uma das condutas mais comumente utilizadas diante dessas situações é a medicalização, tratando com benzodiazepínicos, por exemplo, o que não resolve o problema; leva à cronificação do quadro clínico, apresenta uma série de efeitos adversos e não permite a explicitação dos problemas de base, dificultando ainda mais o desenvolvimento de estratégias coletivas de superação dos problemas.

De acordo com Victor Valla (1996, apud Lacerda \&Valla ${ }^{25}$ ), os profissionais de saúde precisam reconhecer que, diante da dificuldade de se lidar com situações de sofrimento difuso, " a crise de interpretação é nossa”. Para esse autor, por partirmos de idéias preconcebidas que consideramos portadoras de verdade, não escutamos adequadamente as falas da população, não nos atemos aos seus discursos, e não nos abrimos a compreender o modo como operam seus saberes. Colocando nossos conhecimentos científicos como centro do processo de trabalho, e não a vida dos sujeitos, estaríamos construindo modos de operar o trabalho em saúde que se desconectam da realidade vivida pelas classes populares 12,24,25.

Torna-se essencial compreender a dinâmica que a própria população tem estruturado em suas estratégias autônomas de produção de vida, evitando julgamentos morais por parte dos profissionais de saúde. Nos últimos anos, por exemplo, as igrejas evangélicas têm representado uma das buscas mais comuns realizadas pelas classes populares. Ao mesmo tempo em que as igrejas podem estar relacionadas a práticas indesejáveis de disciplinarização 32 e controle 33 , em algumas situações, para alguns autores, elas também se apresentariam como lugares: onde as pessoas podem ser acolhidas e cuidadas; que trabalham com as emoções e afetos, gerando sensação de pertencimento a coletivos; em que se constroem redes de solidariedade capazes de resolver problemas de âmbito financeiro e afetivo; onde se afirmam relações que se baseiam em valores às vezes contrários aos interesses gerais da sociedade capitalista que os oprime e com os quais os sujeitos não querem se identificar; também, onde se consegue encontrar explicações para as coisas desordenadas e que passam a dar sentido às suas vidas 24,31,34,35,36. Lacerda et al. 34 chegam a identificar várias semelhanças entre os trabalhos desenvolvidos nas classes populares pelos pastores evangélicos e os papéis que vêm desempenhando os agentes comunitários de saúde das equipes de saúde da família. Sendo assim, seria importante construir um diálogo com os agentes religiosos presentes nos grupos sociais, independentemente da opção religiosa do profissional de saúde. É relevante identificar o modo como essas instituições religiosas podem ou não representar e fortalecer buscas de melhorias para a vida das pessoas, e produzir as parcerias necessárias para minimizar possíveis propostas que tendam a dificultar a construção de alternativas coletivas para os problemas de saúde da população 11,34.

Lacerda \& Valla 30 consideram o apoio social como um trabalho que busca o autocuidado ou o desenvolvimento de ambientes saudáveis como uma das dimensões de práticas ou de sistemas de saúde que se orientam por meio da perspectiva da promoção da saúde. No conceito de apoio social, agrega-se um conjunto de atividades que podem ter resultados favoráveis no enfrentamento dos problemas de saúde-doença, e que se estruturam mediante diversas relações solidárias que se estabelecem entre os sujeitos. Essas relações podem se desenvolver ao se mobilizarem sistematicamente o conjunto de recursos emocionais, materiais e de informação a partir de relações íntimas e familiares ou até em grupos sociais maiores. As várias estratégias que desenvolvem o apoio social buscam ajudar na constituição de sujeitos que tenham capacidade de definir os rumos de suas próprias vidas, de ampliar sua autonomia. Essa situação leva os sujeitos a terem maior possibilidade de responder aos fatores estressantes e passam a lidar melhor com as adversidades da 
vida, levando a melhorias na saúde física e mental 24,25. Ao trabalhar com a concepção de que a origem das doenças, bem como a sua superação, necessariamente está relacionada com as emoções que são mobilizadas pelos sujeitos, o apoio social se suporta em abordagens que privilegiam a totalidade corpo-mente, não considerando estas como dimensões distintas dos sujeitos. $\mathrm{O}$ apoio social apresenta caráter de reciprocidade, trazendo efeitos favoráveis para todos os envolvidos, estejam aparentemente oferecendo ou recebendo o apoio, fortalecendo a compreensão de que as pessoas necessitam umas das outras para construírem relações de cuidado integrais 24,29 .

Nessa perspectiva, o apoio social se desenvolveria e se potencializaria por meio da articulação em uma rede social, que se configura como uma teia que agrega e conecta os indivíduos; uma teia de vínculos sociais que permite uma circulação dos recursos tangíveis e intangíveis mobilizados pelo apoio social. Esse apoio desenvolvido em redes de solidariedade possibilitaria o fortalecimento da singularidade dos sujeitos e os tensionaria a serem portadores de projetos para a própria vida, além de que reforçaria laços que criam uma sensação de pertencimento coletivo, melhorando sua saúde de modo integral em âmbito individual e coletivo 25,37.

Reconhece-se que as redes de apoio social geralmente se desenvolvem com base em articulações autônomas dos usuários; mesmo assim, os profissionais de saúde poderiam potencializar o apoio social: ajudando a desarticular redes sociais prejudiciais; identificando as redes sociais que circundam os usuários e estão envolvidas no seu adoecimento ou podem ser utilizadas para facilitar o enfretamento de seus problemas; fortalecendo redes sociais positivas existentes; estimulando a configuração de novos arranjos coletivos entre a população e os recursos disponíveis. Tais atitudes ajudariam no processo terapêutico ao tornar conscientes, para os usuários, processos muitas vezes não identificados pelos mesmos, e permitir aos profissionais atuar em campos ainda não explorados em sua intervenção. Dependendo da complexidade do problema, os próprios profissionais de saúde também precisariam estar articulados em redes que ampliassem o cuidado aos usuários e seus familiares 24,25,29.

Sendo assim, a relação profissional de saúde/usuário poderia ser compreendida como produtora de apoio social, seja como apoio informativo ou emocional 25. O apoio informativo se estrutura na relação dialógica que se estabelece no trabalho em saúde, enquanto o apoio emocional se desenvolve a partir do modo como se configuram as relações baseando-se nas atitudes do profissional diante do usuário. $\mathrm{Na}$ verdade, ambas as dimensões do apoio estão intrinsecamente articuladas, pertencendo a um mesmo processo, e elas poderiam ser potencializadas quando o profissional centra suas ações não nos conhecimentos que domina, e sim nas tecnologias leves do trabalho vivo operando em ato ${ }^{38}$. Trataria-se de permitir que os afetos e afetações desencadeados na relação fizessem parte e orientassem as condutas do profissional de saúde 25 .

A Terapia Comunitária é uma técnica de trabalho com grupos que se baseia no relato da história de vida dos participantes e do modo como cada um lida com suas dificuldades do cotidiano. Para alguns autores, o relato e a escuta atenta permitiria que as emoções circulassem e fossem ressignificadas pelos sujeitos, fortalecendo-os e aos processos coletivos em que se inserem. A Terapia Comunitária integraria, assim, as ações de prevenção e promoção à saúde que tomam como foco o sujeito e não as doenças 31. Entretanto, é importante salientar que práticas de Terapia Comunitária não podem ser desenvolvidas de forma desarticulada de outros modos de luta social, para evitar que seu resultado seja mera resignação ou culpabilização dos sujeitos.

$\mathrm{Na}$ análise de Lacerda \& Valla ${ }^{30}$, o apoio social se aproxima do paradigma "sistema da dádi$v a$, que se estrutura na obrigatoriedade da tríade dar-receber-retribuir, fazendo com que os bens materiais e simbólicos possam fluir em trocas sistemáticas entre os diferentes laços e vínculos das redes sociais que se constituem.

\section{Para fazer avançar a educação popular nos serviços de saúde}

Os próprios autores que produzem na perspectiva da educação popular em saúde reconhecem que há muitos avanços na expectativa dela se desenvolver junto aos serviços de saúde, entretanto, tais avanços não teriam ainda sido suficientes para mudar o modo como o modelo hegemônico vem sendo implantado, pois seria necessário que mais do que apenas alguns trabalhadores desempenhando este papel 21 . Haveria, entre os profissionais de saúde, a compreensão de que não é preciso aprender a fazer educação em saúde, bastando para tanto o seu conhecimento clínico; somaria-se a isto a pouca oferta de formação e de processos de educação permanente no conjunto dos municípios, fruto da inexistência de política com tal finalidade 20 . Tal situação estaria limitando o avanço das ações de educação popular em saúde. Seria necessário o desenvolvimento de políticas mais intensivas de formação de profissionais de saúde que 
considerassem a educação popular como método nas suas formações 21 .

É feita a crítica de que, muitas vezes, as experiências de educação popular em saúde são desenvolvidas apenas por iniciativa dos profissionais, sem que houvesse uma política específica de indução por parte dos gestores municipais, chegando mesmo a ocorrer resistências por parte destes 20. Diante dessas situações, seria importante construir estratégias de disputa dos distintos projetos políticos junto à sociedade. Tal caminho se tornaria mais difícil, entretanto, quando encontramos os trabalhadores com vínculos empregatícios precários, situação ainda extremamente comum em diversas localidades, por fragilizar estes atores diante dos que ocupam posição de governo.
Resumo

O artigo revisa a produção acadêmica brasileira sobre a educação popular em saúde, matriz teórica que agrega um conjunto relevante de pesquisadores e militantes políticos na saúde coletiva brasileira. Caracteriza-se como uma pesquisa de natureza qualitativa, de nível exploratório e de caráter analítico. Com base em pesquisa bibliográfica no SciELO e em livros e capítulos de livros, elaboramos uma sistematização da produção da educação popular em saúde, apresentando um resgate do processo histórico de constituição da educação popular em saúde como fruto da atuação de diversos movimentos sociais, uma descrição das características gerais da educação popular em saúde, suas grandes pautas, a maneira como os autores desta perspectiva compreendem a atuação educativa dos serviços de saúde junto à população, suas críticas e disputas com o modo hegemônico de se organizar a educação $e$ a atenção à saúde, bem como algumas contribuições que agregam aos que se propõem a seguir suas bases e preceitos.

Educação em Saúde; Participação Comunitária; Pesquisa Qualitativa
A tentativa de incorporar a educação popular à atenção à saúde nos grandes centros urbanos tem enfrentado tanto o poder político como o econômico dominante, hegemônicos na lógica de funcionamento dos serviços de saúde, como a injusta distribuição de recursos por parte do Estado, que na maioria das vezes não privilegia os setores sociais 12. A expansão da educação popular em saúde exigiria que, aos movimentos desencadeados pelos trabalhadores nos serviços de saúde, se somassem iniciativas de gestores nas três esferas de governo 21 .

\section{Colaboradores}

L. B. Gomes participou da concepção do projeto, realizou a pesquisa em bases de dados e sua análise, e elaborou a redação final do artigo. E. E. Merhy participou da concepção do projeto, orientou a pesquisa em bases de dados e sua análise, revisou e orientou a redação final do artigo.

\section{Agradecimentos}

Os autores gostariam de agradecer a todos os integrantes da linha de pesquisa Micropolítica do Cuidado e o Trabalho em Saúde, da Pós-graduação em Clínica Médica, da Faculdade de Medicina da Universidade Federal do Rio de Janeiro, pelas contribuições inestimáveis nos debates realizados ao longo da elaboração desta pesquisa. 


\section{Referências}

1. Merhy EE. A saúde pública como política - São Paulo, 1920-1948: os movimentos sanitários, os modelos tecno-assistenciais e a formação das políticas governamentais. São Paulo: Editora Hucitec; 1992. (Saúde em Debate, 50).

2. Deleuze G, Guattari F. Mil platôs: capitalismos e esquiozofrenia. v. 2. Rio de Janeiro: Editora 34; 1997.

3. Deleuze G. O abecedário de Gilles Deleuze [vídeo]. Produção de Éditions Montparnasse, realização de Pierre-André Boutang. Brasília: TV Escola; 1988/1989.

4. Gil AC. Métodos e técnicas de pesquisa social. 5a Ed. São Paulo: Atlas; 1999.

5. Marconi MA, Lakatos EM. Técnicas de pesquisa: planejamento e execução de pesquisas, amostragens e técnicas de pesquisa, elaboração, análise e interpretação de dados. 7a Ed. São Paulo: Atlas; 2008.

6. Gil AC. Como elaborar projetos de pesquisa. 4 a Ed. São Paulo: Atlas; 2002.

7. Schwandt TA. Três posturas epistemológicas para a investigação qualitativa. In: Denzin N, Lincoln Y, organizadores. O planejamento da pesquisa qualitativa - teorias e abordagens. 2a Ed. Porto Alegre: Artmed Bookman; 2006. p. 193-218.

8. Minayo MCS. O desafio do conhecimento: pesquisa qualitativa em saúde. 4a Ed. São Paulo: Editora Hucitec/Rio de Janeiro: ABRASCO; 1996.

9. Eco U. Como se faz uma tese. 17ạ Ed. São Paulo: Perspectiva; 2001.

10. Vasconcelos EM. Participação popular e educação nos primórdios da saúde pública brasileira. In: Vasconcelos EM, organizador. A saúde nas palavras e nos gestos: reflexões da Rede de Educação Popular nos Serviços de Saúde. São Paulo: Editora Hucitec; 2001. p. 73-100.

11. Vasconcelos EM. Educação popular nos serviços de saúde. 3a Ed. São Paulo: Editora Hucitec; 1997.

12. Vasconcelos EM. Educação popular e a atenção à saúde da família. 4a Ed. São Paulo: Editora Hucitec; 2008.

13. Merhy EE. A rede básica como uma construção da saúde pública e seus dilemas. In: Merhy EE, Onocko R, organizadores. Agir em saúde: um desafio para o público. 2a Ed. São Paulo: Editora Hucitec; 2002. p. 197-228. (Saúde em Debate, 108/Série Didática, 6).

14. Elias PEM. Estrutura e organização da atenção à saúde no Brasil. In: Cohn A, Elias PEM, organizadores. Saúde no Brasil: políticas e organização de serviços. 3a Ed. São Paulo: Editora Cortez/Centro de Estudos de Cultura Contemporânea; 1999. p. 59-119.

15. Brasil. Constituição 1998: texto constitucional de 5 de outubro de 1998, com as alterações adotadas pelas Emendas Constitucionais de revisão $\mathrm{n}^{\circ} .1$ a 6/94. Brasília: Senado Federal; 2000.

16. Brasil. Lei no ${ }^{\circ}$. 8.080, de 19 de setembro de 1990 Dispõe sobre as condições para a promoção, proteção e recuperação da saúde, a organização e o funcionamento dos serviços correspondentes e dá outras providências. Diário Oficial da União 1990; 19 set.
17. Brasil. Lei $n^{\circ} 8.142$, de 28 de dezembro de 1990 . Dispõe sobre a participação da comunidade na gestão do Sistema Único de Saúde (SUS) e sobre as transferências intergovernamentais de recursos financeiros na área da saúde e dá outras providências. Diário Oficial da União 1990; 28 dez.

18. Stotz EM, David HSL, Wong-Un JA. Educação popular e saúde: trajetória, expressões e desafios de um movimento social. Rev APS 2005; 8:49-60.

19. Pedrosa JIS. Educação popular no Ministério da Saúde: identificando espaços e referências. In: Ministério da Saúde, organizador. Caderno de educação popular e saúde. Brasília: Ministério da Saúde; 2007. p. 13-7.

20. Albuquerque PC, Stotz EN. A educação popular na atenção básica à saúde no município: em busca da integralidade. Interface Comun Saúde Educ 2004; 8:259-74.

21. Vasconcelos EM. Educação popular: de uma prática alternativa a uma estratégia de gestão participativa das Políticas de Saúde. Physis (Rio J.) 2004; 14:67-83.

22. Freire P. Pedagogia da autonomia: saberes necessários à prática educativa. São Paulo: Paz e Terra; 1996. (Coleção Leitura).

23. Vasconcelos EM. Educação popular como instrumento de reorientação das estratégias de controle das doenças infecciosas e parasitárias. Cad Saúde Pública 1998; 14 Suppl 2:39-57.

24. Valla VV, Guimarães MB, Lacerda A. Religiosidade, apoio social e cuidado integral à saúde: uma proposta de investigação voltada para as classes populares. In: Pinheiro R, Mattos RA, organizadores. Cuidado: as fronteiras da integralidade. 3a Ed. Rio de Janeiro: Centro de Estudos e Pesquisa em Saúde Coletiva, Instituto de Medicina Social, Universidade do Estado do Rio de Janeiro/ABRASCO; 2006. p. 103-17.

25. Lacerda A, Valla VV. Um olhar sobre a construção social da demanda a partir da dádiva e das práticas de saúde. In: Pinheiro R. Mattos RA, organizadores. Construção social da demanda: direito à saúde, trabalho em equipe, participação e espaços públicos. Rio de Janeiro: Centro de Estudos e Pesquisa em Saúde Coletiva, Instituto de Medicina Social, Universidade do Estado do Rio de Janeiro/ ABRASCO; 2005. p. 279-92.

26. Machado FRS, Pinheiro R, Guizardi FL. As novas formas de cuidado integral nos espaços públicos de saúde. In: Pinheiro R, Mattos RA, organizadores. Cuidado: as fronteiras da integralidade. 3a $\mathrm{Ed}$. Rio de Janeiro: Centro de Estudos e Pesquisa em Saúde Coletiva, Instituto de Medicina Social, Universidade do Estado do Rio de Janeiro/ABRASCO; 2006. p. 75-90.

27. Carriconde C. Introdução ao uso de fitoterápicos nas patologias de APS. Olinda: Centro Nordestino de Medicina Popular; 2002.

28. Medeiros LCM, Cabral IE. O cuidar com plantas medicinais: uma modalidade de atenção à criança pelas mães e enfermeira-educadora. Rev Latinoam Enferm 2001; 9:18-26. 
29. Valla VV. Educação popular, saúde comunitária e apoio social numa conjuntura de globalização. Cad Saúde Pública 1999; 15 Suppl 2:7-14.

30. Lacerda A, Valla VV. Homeopatia e apoio social: repensando as práticas de integralidade na atenção e no cuidado à saúde. In: Pinheiro R, Mattos RA, organizadores. Construção da integralidade: cotidiano, saberes e práticas em saúde. 3a Ed. Rio de Janeiro: Centro de Estudos e Pesquisa em Saúde Coletiva, Instituto de Medicina Social, Universidade do Estado do Rio de Janeiro/ABRASCO; 2005. p. 169-96.

31. Lacerda A, Guimarães MB, Lima CM, Valla VV. Cuidado integral e emoções: bens simbólicos que circulam nas redes de apoio social. In: Pinheiro R, Mattos RA, organizadores. Razões públicas para a integralidade: o cuidado como valor. Rio de Janeiro: Centro de Estudos e Pesquisa em Saúde Coletiva, Instituto de Medicina Social, Universidade do Estado do Rio de Janeiro/ABRASCO; 2007. p. 249-62.

32. Foucault M. Microfísica do poder. 20a Ed. Rio de Janeiro: Edições Graal; 2004.

33. Deleuze G. Conversações, 1972-1990. São Paulo: Editora 34; 1992.

34. Lacerda A, Valla VV, Guimarães MB. A qualidade do cuidado na convivência com os pobres: o trabalho dos pastores e dos agentes comunitários de saúde. In: Pinheiro R, Mattos RA, organizadores. Construção social da demanda: direito à saúde, trabalho em equipe, participação e espaços públicos. Rio de Janeiro: Instituto de Medicina Social, Universidade do Estado do Rio de Janeiro/ABRASCO; 2005. p. 267-78.
35. Lacerda A, Guimarães MB, Valla VV, Lima CM. As redes participativas da sociedade civil no enfrentamento dos problemas de saúde. In: Pinheiro R, Mattos RA, organizadores. Gestão em redes: práticas de avaliação, formação e participação na saúde. Rio de Janeiro: Centro de Estudos e Pesquisa em Saúde Coletiva, Instituto de Medicina Social, Universidade do Estado do Rio de Janeiro; 2006. p. 445-58.

36. Vasconcelos EM. A espiritualidade no cuidado e na educação em saúde. In: Vasconcelos EM, organizador. A espiritualidade no trabalho em saúde. São Paulo: Editora Hucitec; 2006. p. 13-157.

37. Lacerda A, Valla VV. As práticas terapêuticas de cuidado integral à saúde como proposta para aliviar o sofrimento. In: Pinheiro R, Mattos RA, organizadores. Cuidado: as fronteiras da integralidade. 3a Ed. Rio de Janeiro: Centro de Estudos e Pesquisa em Saúde Coletiva, Instituto de Medicina Social, Universidade do Estado do Rio de Janeiro/ABRASCO; 2006. p. 91-102.

38. Merhy EE. Em busca do tempo perdido: a micropolítica do trabalho vivo em saúde. In: Merhy EE, Onocko R, organizadores. Agir em saúde: um desafio para o público. 2ạ Ed. São Paulo: Editora Hucitec; 2002. p. 71-112. (Saúde em Debate, 108/Série Didática, 6).

Recebido em 24/Abr/2010

Versão final reapresentada em 04/Out/2010 Aprovado em 08/Out/2010 